\title{
Pelatihan Kewirausahaan Bina Bisnis Online Pemasaran Produk Makanan Dan Reseller Untuk Kelompok Perwiridan Al Mubarok
}

\author{
Devit Satria *1, Muhammad Arif ${ }^{2}$, Elisa Hafrida ${ }^{3}$ \\ 1,2,3 Sekolah Tinggi Teknologi Dumai \\ ${ }^{1}$ Program Studi Teknik Informatika, 2,3Teknik Industri Sekolah Tinggi Teknologi (STT) Dumai \\ *e-mail: devitsatriasttd@gmail.com¹, pakarifmt@gmail.com, hafridae@gmail.com
}

\begin{abstract}
Based on the results of field observations and interviews (January, 2021) with partners, namely an association of wirid women named Al Mubarok in Bukit Nenas Village. Members of mothers who have several desires have a good online business marketing and become an online business reseller to increase their income. So far, it looks more like posting on WA groups and on FB or IG Status as usual. There is also the manufacture of food products and only reseller activities whose income results are not optimal according to the recognition of these activity partners. The participants were very enthusiastic to take part in this activity, as evidenced by their timely arrival. Entrepreneurship training was conducted for residents of Bukit Nenasl Village RT 013 to be able to participate in the business world of selling and producing wet and dry food and other selling products. Participants can design their new online business, the process and stages of making promotions through social media applications so that it is more optimal than the previous way of business.
\end{abstract}

Keywords:Online Business, Marketing, Reseller

\begin{abstract}
Abstrak
Berdasarkan hasil observasi lapangan dan wawancara (Januari, 2021) dengan mitra, Yaitu sebuah perkumpulan wirid ibu-ibu yang bernama Al Mubarok di Kelurahan Bukit Nenas. Beranggotakan ibu-ibu yang memiliki beberapa keingainan mempunyai pemasaran bisnis secara online yang baik serta menjadi reseller bisnis online untuk menambah penghasilan mereka. Selama ini lebih terlihat seperti memposting di grup WA dan di Satatus FB maupun IG secara biasa saja. Ada juga pembuatan produk makanan dan kegiatan reseller saja yang belum optimal hasil pendapatannya menurut pengakuan mitra kegiatan ini. Para peserta sangat antusias untuk mengikuti kegiatan ini, dibuktikan dengan kedatangan mereka yang tepat waktu.. Pelatihan kewirausahaan dilakukan bagi warga Kelurahan Bukit Nenasl RT 013 untuk dapat berperan serta dalam dunia usaha penjualan maupun produksi makanan basah maupun kering serta produk jualan lainnya. Peserta dapat merancang bisnis online baru mereka, proses dan tahapan pembuatan promosi melalui aplikasi social media sehingga lebih optimal dibandingkan dengan bisnis cara sebelumnya.
\end{abstract}

Kata kunci: Bisnis Online, pemasaran, Reseller

\section{PENDAHULUAN}

Berdasarkan hasil observasi lapangan dan wawancara (Januari, 2021) dengan mitra, Yaitu sebuah perkumpulan wirid ibu-ibu yang bernama Al Mubarok di Kelurahan Bukit Nenas. Beranggotakan ibu-ibu yang memiliki beberapa keingainan mempunyai pemasaran bisnis secara online yang baik serta menjadi reseller bisnis online untuk menambah penghasilan mereka. Adapun kondisi / Eksisting dari mitra adalah sebagai berikut (1) Masyarakat atau warga perumahan tertarik untuk memperoleh penjelasan tentang cara berwiraswasta yang mengarah kepada pembuatan produk makanan yang meliputi manajemen produksi dan metode pemasarannya secara online, sehingga tim menawarkan kepada masyarakat untuk membuat pelatihan kewirausahaan dan pendampingan selama tiga bulan kepada kelompok perwiridan ibuibu Al Mubarok di wilayah perumahan tersebut. (2) Masyarakat perumahan masih 
belum mengetahui manfaat dan cara detail manajemen produksi dan pemasaran dari produk maupun reseller produk yang dijual secara online, sebagai salah satu peluang bisinis kedepannya. (3) Adanya keterbatasan dalam informasi tentang bisnis online dan semangat kewirausahaan terhadap usaha penjualan produk maupun reseller produk yang ada di sistem online sehingga perlu dibuat melalui suatu kegiatan training dan pendampingan.Berdasarkan analisa situasi diatas, Tim Dosen Sekolah Tinggi Teknologi Dumai tertarik untuk mengadakan Pengabdian Kepada Masyarakat Bagi kelompok Perwiridan Al Mubarok di Perumahan Bukit Nenas Regency Kelurahan Bukit Nenas dangan bekerjasama melalui Bapak Ketua RT 013 sebagai tokoh masyarakat di perumahan tersebut.

Pengabdian yang mengarah kepada pendampingan entrepeanurship lebih bermanfaat dari pada penyuluhan biasa yang menjadi kegiatan PPM ke masyarakat mitra, terbukti dari keberanian mitra memulai usaha denga lebih yakin, Social media dapat digunakan sebagai sarana dalam meningkatkan jaringan atau koneksi dalam menawarkan produk/jasa kita, dan untuk berhasil mencapai hal tersebut, kita dapat menggunakan strategi internal dan eksternal (Gamayanto 2021).Pesatnya perkembangan teknologi khususnya e-commerce memberikan dampak pada perubahan perilaku para wirausaha dalam berbisnis, hal tersebut dikarenakan prosesnya menjadi lebih mudah dan meminimalisir biaya operasional yang keluar (Aqmala et al., 2020). Sedangkan pemanfaatan digital marketing untuk komersialisasi produk yang di tawarkan juga menjadi solusi dalam pemasaran produk, dibandingkan cara lama yng menempatkan di kedai atau warung saja (Ernawati, 2021). Pentahapan proses dilakukan secara konsisten selama kegiatan pendampingan sehingga dapat berkontribusi bagi terciptanya suasana kebersamaan yang mempercepat pencapaian sasaran yang ditargetkan (Kurniawan 2021). Pada awal kemunculannya e-commerce memberikan dampak sangat signifikan pada fungsi penggunaannya sebagai media bisnis online (Muhartia \& Rinawati, 2017)Hingga saat ini transaksi yang dilakukan menggunakan media e commerce masih berdasarkan asas kepercayaan karena belum adanya sistem yang mengatur keamanan dalam bertransaksi (Wibowo, 2016)

\section{METODE}

Metode pelaksanaan pada Pengabdian Pada Masyarakat (PPM) adalah dengan mengadakan pelatihan dan workshop untuk membantu manajemen produksi dan pemasaran yang lebih baik terhadap produk makanan dan reseller produk lainnya bagi ibu-ibu warga Perumahan Baruna terutama warga masyarakat RT 013 yang rata-rata memiliki kegiatan penjulanan dan penawaran produk makanan dan reseeler di grup wa dan mesdsos lainnya. Proses pelaksanaan pelatihan kemitraan masyarakat ini akan terdiri dari metode antara lain.Pembuatan modul pelatihan Sebelum pelatihan dilaksanakan terlebih dahulu tim dosen membuat modul yang akan digunakan dalam mengikuti proses pelatihan produksi dan pemasaran produk secara online via handphone android ke dalam aplikasi sosmed dengan cara yang lebih efektif. Pelaksanaan Pelatihan. Pelatihan dilaksanakan di Perumahan Bukit Nenas Regency Kelurahan Bukit Nenas. Materi pelatihan diberikan oleh tim dosen. Materi tentang manajemen produksi dan pemasarannya secara online disampaikan dalam presentasi, diskusi dan tanya jawab selama kegiatan dilakukan. Materi pelatihan kemitraan masyarakat terlampir di lampiran. 


\section{HASIL DAN PEMBAHASAN}

Pelaksanaan kegiatan PPM ini dengan judul "Pelatihan Kewirausahaan Bina Bisnis Online Pemasaran Produk Makanan dan Reseller Untuk Kelompok Perwiridan Al Mubarok" telah selesai dilakukan. Berikut ini merupakan hasil yang dicapai dalam pengabdian ini.

Tabel 1. Rekapitulasi Keaktifan dan Hasil Luaran Diklat Kewirausahaan

\begin{tabular}{|c|c|c|}
\hline \multicolumn{3}{|c|}{ Persiapan } \\
\hline Langkah & Tujuan & Hasil \\
\hline $\begin{array}{l}\text { Pembentukan } \\
\text { kegiatan }\end{array}$ & $\begin{array}{lr}\text { Membuat } & \text { struktur } \\
\text { kepanitian } & \text { dan } \\
\text { pembagian tugas } & \end{array}$ & $\begin{array}{l}\text { Struktur kepanitian } \\
\text { terdiri dari tim dosen } \\
\text { STT Dumai }\end{array}$ \\
\hline Administrasi kegiatan & $\begin{array}{ll}\text { Mengelola } & \text { kegiatan dan } \\
\text { bukti } & \text { pelaksanaan } \\
\text { pengabdian } & \end{array}$ & $\begin{array}{l}\text { Daftar hadir peserta dan } \\
\text { tim dosen, berita acara } \\
\text { pelaksanaan kegiatan } \\
\text { pengabdian }\end{array}$ \\
\hline $\begin{array}{l}\text { Pembuatan modul dan } \\
\text { banner pelatihan }\end{array}$ & $\begin{array}{l}\text { Membuat modul dan } \\
\text { banner untuk peserta dan } \\
\text { sebagai bahan presentasi }\end{array}$ & $\begin{array}{l}\text { Materi pelatihan : } \\
\text { Pelatihan Kewirausahaan } \\
\text { Bina Bisnis Online } \\
\text { Pemasaran Produk } \\
\text { Makanan dan Reseller }\end{array}$ \\
\hline
\end{tabular}

\section{Pelaksanaan}

\begin{tabular}{|c|c|c|}
\hline Langkah & Tujuan & Hasil \\
\hline Pelaksanaan Pelatihan & Pelaksanaan pelatihan & Pelaksanaan pelatihan \\
\hline \multicolumn{3}{|c|}{ Penutup } \\
\hline Langkah & Tujuan & Hasil \\
\hline Evaluasi kegiatan & $\begin{array}{l}\text { Mengetahui hal - hal yang } \\
\text { belum sesuai dengan yang } \\
\text { diharapkan }\end{array}$ & $\begin{array}{l}\text { Saran untuk perbaikan } \\
\text { Kegiatan PKM Selanjutnya }\end{array}$ \\
\hline Laporan kegiatan & $\begin{array}{l}\text { Melaporkan Kegiatan PKM } \\
\text { yang telah dilakukan }\end{array}$ & $\begin{array}{l}\text { Laporan Akhir Kegiatan } \\
\text { PKM }\end{array}$ \\
\hline
\end{tabular}

Kegiatan pengabdian ini telah dilaksanakan hari Rabu 2 Juni 2021 di RT 013 Kelurahan Bukit Nenas. Kegiatan ini diisi dengan materi mengenai pelatihan motivasi kewirausahaan oleh bapak Muammad Arif, MT dan dilanjutkan persyaratan higienis pada makanan oleh ibu Elisa Hafrida, M.Kes, lalu terakhir tentang pelaksanakan bisnis online dan reseller dengan menggunakan aplikasi Ig, FB, dan WA yang dibawakan oleh pak Devit Setria, M.Pd.T.. Jumlah peserta diikuti oleh 15 orang peserta. Para peserta sangat antusias untuk mengikuti kegiatan ini, dibuktikan dengan kedatangan mereka yang tepat waktu. Antusiasme juga terlihat dalam mendengarkan penjelasan dari pemateri dan banyaknya pertanyaan yang diajukan seputar materi yang diberikan. Walaupun diakhir sesi kegiatan disediakan waktu khusus untuk tanya jawab, namun beberapa peserta juga mengajukan pertanyaan disela-sela materi diberikan. 
Materi diberikan dalam tiga sesi dan diakhiri dengan sesi Tanya jawab. Materi pertama adalah menjelaskan bagaimana ide dan perlunya motifasi untuk berwirausaha bagi para ibu-ibu perwiridan Al Mubarok nantinya. Lalu materi tentang

higienis makanan dan penyajiannya, den terakhir bagaimana melaksanakan bisnis online dan reseller dengan bantuan aplikasi medsos yang sudah ada.

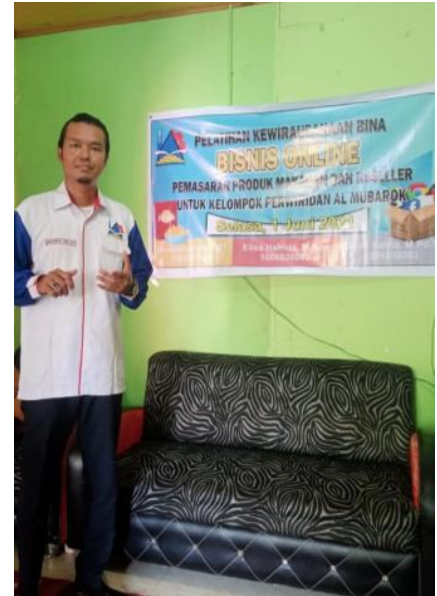

(a)

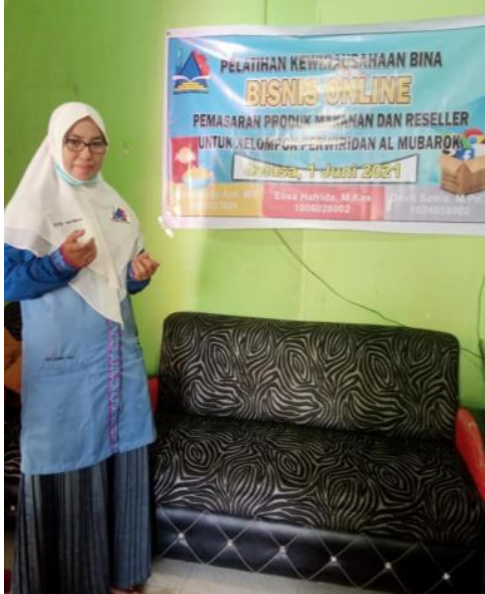

(b)

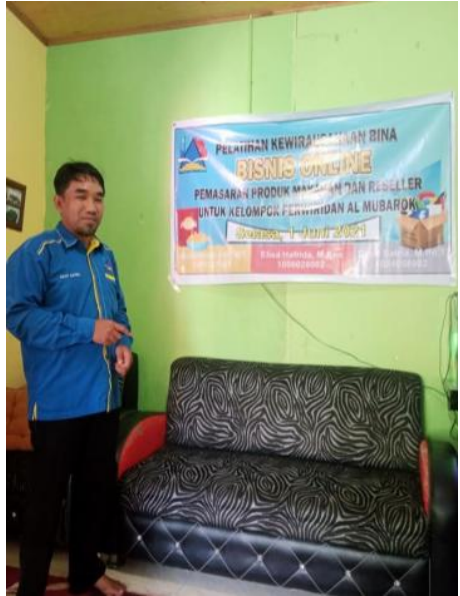

(c)

Gambar 1. Tim Pengabdian (a) Muhammad Arif, (b) Elisa Harfida, (c) Devit Satria

Materi pelatihan kewirausahaan bisnis online ini disampaikan oleh Tim STT Dumai yang telah dilaksanakan didepan peserta training dan workshop usaha bisnis makanan perwiridan al Mubarok Bukit Nenas.

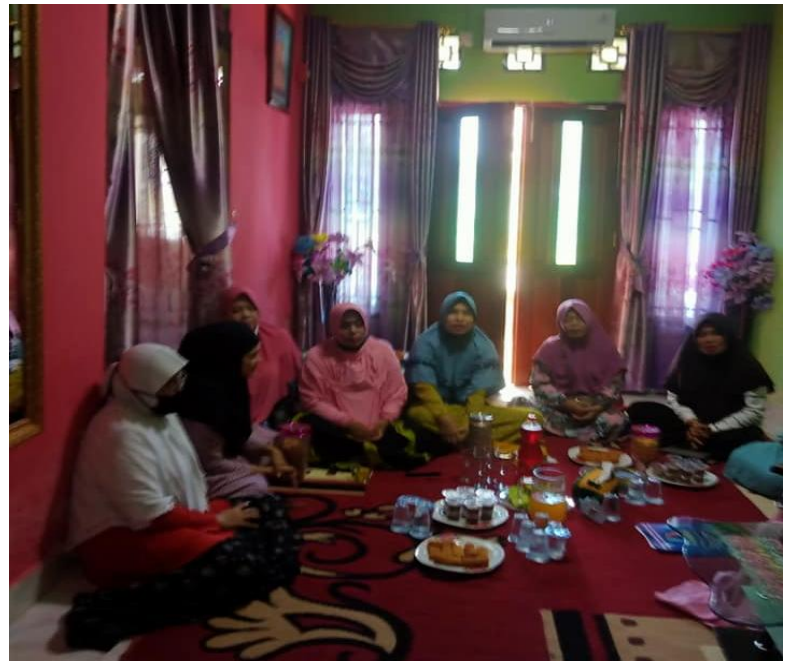

(a)

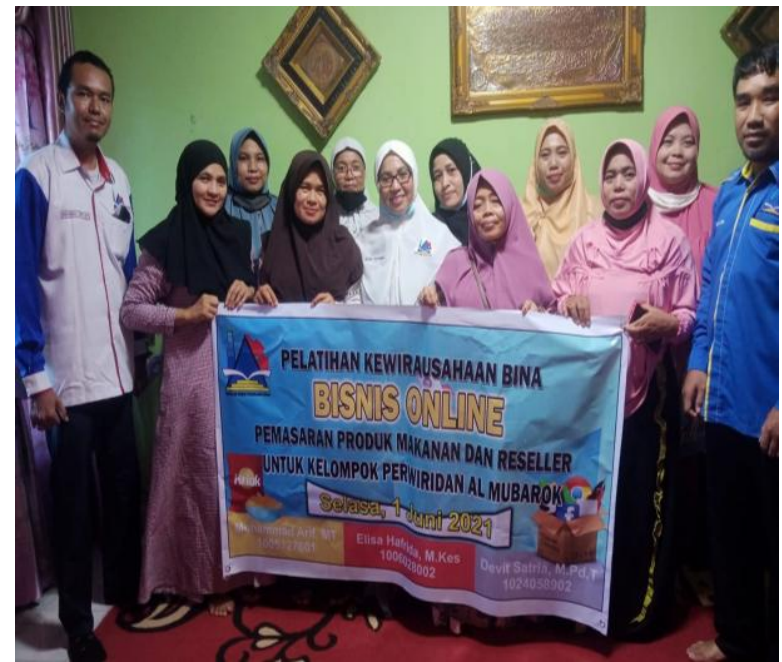

(b)

Gambar 2. (a) Peserta Pengabdian, (b) Penutupan Acara Pengabdian

Sesi terakhir dilakukan tanya jawab seputar kegiatan memulai usaha, prospek usaha dan motifasi berbisnis makanan dengan system online bagi peserta pelatihan. Semoga dengan adanya materi kewirausahaan ini membantu pemahaman ibu-ibu peserta untuk berani memulai usaha bisnis online dan reseller denganlebih optimal dan menguntungkan di masa mendatang.

Dari beberapa poto yang ada dapat digambarkan kegiatan selama penyuluhan yang berlangsung melalui cara training dan workshop bisnis online yang terlaksana 
pada tanggal 2 Juni 2021 tersebut. Sesi terakhir kegiatan pengabdian ini adalah sesi tanya jawab. Disini para peserta secara aktif mengajukan pertanyaan yang berkaitan dengan cara memulai bisnis online dan memanfaatkan aplikasi social media yang ada agar dapat berpromosi maupun bertransaksi dengan pembeli mereka nantinya. Beberapa pertanyaan yang diajukan misalanya kelebihan dan kelemahan menjalankan bisnis online, kendala dalam melakukan bisnis online ini, dan bagaimana cara memulai semangat berwirausaha bisnis online yang lebih menguntungkan agar lebih efektif dan efisien sebagi bisnis baru masyarakat di Kelurahan Bukit Nenas.

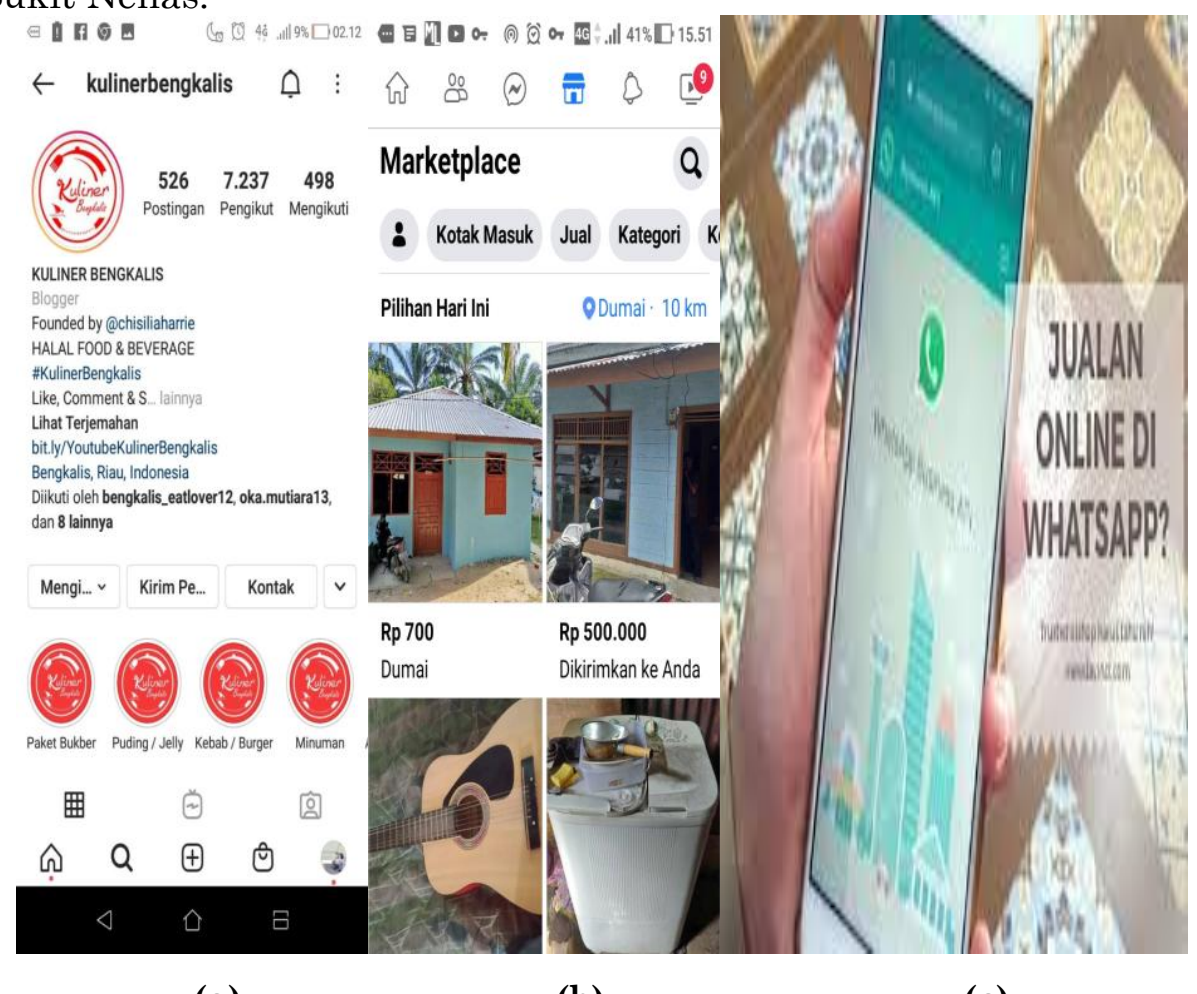

(a)

(b)

(c)

Gambar 3. (a) Histagram,(b) Facebook,(c) Whatsapp

\section{KESIMPULAN}

Pelatihan kewirausahaan memulai bisnis onlineproduk makanan serta reseller ini dilakukan bagi warga Kelurahan Bukit Nenasl RT 013 untuk dapat berperan serta dalam dunia usaha penjualan maupun produksi makanan basah maupun kering serta produk jualan lainnya. Peserta dapat merancang bisnis online baru mereka, proses dan tahapan pembuatan promosi melalui aplikasi social media sehingga lebih optimal dibandingkan dengan bisnis cara sebelumnya.

\section{UCAPAN TERIMA KASIH}

Assalamu'alaikum Wr. Wb

Dengan telah berakhirnya masa pelaksanaan pengabdian kepada Masyarakat Sekolah Tinggi Teknologi Dumai (LPPM STTDumai) pada tanggal 2 Juni 2021, saya beserta anggota mengucapkan terima kasih dan penghargaan atas segala dukungan, bantuan, dan kerjasamanya yang baik selama ini.

Saya mohon maaf yang setulus-tulusnya atas segala kekhilafan dan kekurangan yang terjadi. Semoga kerjasama yang telah terjalin selama ini semakin meningkat dan 
semoga Allah SWT senantiasa melimpahkan rahmat, taufik, dan hidayahnya kepada kita sekalian. Amin.

\section{DAFTAR PUSTAKA}

Aqmala, D., Putra, F.I.F.S., Suseno, A. (2020). Faktor-faktor yang Membentuk Minat Berwirausaha Mahasiswa Program Studi Manajemen Universitas Dian Nuswantoro. Dayasaing: Jurnal Manajemen Sumber Daya, 22(1), 60-70.

Ernawati. (2021). Peningkatan Keahlian Identifikasi Peluang Usaha Bagi Calon Wirausaha di Kota Kendari, Dinamisia,5(1), 89-96

Gamayanto, Indra. (2021). Pelatihan dan Implementasi Social Media Profilling Untuk Meningkatkan Kompetensi Pada SMA Negeri 3 Semarang, Abdimasku, 4(1), 2635

Kurniawan,Andri. (2021). Pendampingan Entrepeaneurship Budidaya Dan Pemasaran Ikan Cupang, Abdimasku, 2(1), 14-19

Muhartia, I. R. and Rinawati, R. (2017) 'Instagram as Media For Marketing Commucation Grow Up Grow Up', in Prosiding Manajemen Komunikasi, pp. 59-65. Wibowo, E. A. (2016). Pemanfaatan Teknologi E-Commerce Dalam Proses Bisnis. Jurnal Equilibiria, 1(1), 95-108. 